\title{
THE EMIGRATION BEHAVIOR OF TWO SPECIES OF THE GENUS PHEIDOLE (FORMICIDAE: MYRMICINAE).
}

\author{
BY ROBERT DROUAL ${ }^{1}$ AND HOWARD TOPOFF ${ }^{2}$
}

\section{INTRODUCTION}

Colony emigrations are common among ants (Wilson 1971) and occur for a diversity of reasons. However, except for the legionary ants, in which colony emigrations are an inherent part of the foraging ecology (Wilson 1971), and species which inhabit delicate and easily disturbed nests (Hölldobler and Wilson 1977, Möglich 1979), emigrations are thought to occur infrequently. Here we present evidence that two species of the genus Pheidole, $P$. desertorum Wheeler and $P$. hyatti Emery, emigrate frequently under environmentally stable conditions. We further advance the hypothesis that the surplus nests resulting from these emigrations, reduce the secondary losses which occur as a consequence of the panic-alarm defense these species employ against army ants of the genus Neivamyrmex, by serving as temporary shelters and centers for colony reorganization.

\section{Methods}

This investigation was conducted during the months of June, July and August, 1980, at two different study sites. One site was an oakjuniper woodland located on the grounds of the Southwestern Research Station of the American Museum of Natural History near Portal, Arizona (elev. $1646 \mathrm{~m}$ ). The other site was a desert-grassland located $8 \mathrm{~km} \mathrm{N.W.} \mathrm{of} \mathrm{Rodeo,} \mathrm{Hidalgo} \mathrm{Co.,} \mathrm{New} \mathrm{Mexico} \mathrm{(elev.} 1250$ m). In both habitats a winter (Dec., Jan., Feb. and March) and a summer (July, June and August) rainy season occur. On the oakjuniper woodland site colonies of both $P$. desertorum and $P$. hyatti were located and marked; on the desert-grassland site only colonies of $P$. desertorum were located and marked.

\footnotetext{
'Biology Program, City College of C.U.N.Y., New York, N.Y. 10031

${ }^{2}$ Psychology Department, Hunter College of C.U.N.Y., New York, N.Y. 10021 and Department of Entomology, The American Museum of Natural History, New York, N.Y. 10024

Manuscript received by the editor June 8, 1981
} 
Table 1. Emigration characteristics of P. hyatti.

\begin{tabular}{|c|c|c|c|c|}
\hline Colony & $\begin{array}{c}\text { Days } \\
\text { Observed }\end{array}$ & $\begin{array}{l}\text { Number of } \\
\text { Emigrations }\end{array}$ & $\begin{array}{l}\text { Returns to a } \\
\text { Former Nest }\end{array}$ & $\begin{array}{c}\text { Distance Between First } \\
\text { and Last Observed } \\
\text { Nests }(\mathrm{m})\end{array}$ \\
\hline H-Jn14-1 & 66 & 6 & 3 & 4.2 \\
\hline H-JnI4-2 & 66 & 16 & 11 & 1.1 \\
\hline H-Jn14-3 & 66 & 8 & 2 & 5.4 \\
\hline H-Jn15-1 & 23 & 1 & 0 & 1.5 \\
\hline H-Jn15-2 & 63 & 7 & 3 & 0.0 \\
\hline H-Jn17-1 & 63 & 0 & 0 & - \\
\hline H-Jn17-2 & 63 & 6 & 2 & 0.8 \\
\hline H-Jn18-1 & 62 & 10 & 5 & 3.2 \\
\hline H-Jn18-2 & 55 & 7 & 2 & 6.8 \\
\hline H-Jn19-1 & 61 & 7 & 4 & 0.0 \\
\hline H-Jn19-2 & 57 & 4 & 1 & 0.0 \\
\hline H-Jn19-3 & 61 & 6 & 2 & 1.5 \\
\hline H-Jn19-4 & 60 & 5 & 2 & 0.0 \\
\hline H-Jn19-5 & 61 & 7 & 5 & 2.0 \\
\hline H-Jn21-1 & 59 & 3 & 0 & 2.6 \\
\hline H-Jn21-2 & 58 & 6 & 4 & 1.9 \\
\hline H-Jn21-3 & 57 & 4 & 2 & 0.0 \\
\hline H-Jn21-4 & 57 & 6 & 3 & 3.0 \\
\hline H-Jn23-1 & 53 & 2 & 0 & 0.8 \\
\hline H-Jn24-1 & 56 & 7 & 1 & 0.8 \\
\hline H-Jn26-1 & 51 & 5 & 1 & 2.5 \\
\hline H-Jn26-2 & 16 & 2 & 0 & 1.1 \\
\hline H-Jn27-1 & 46 & 8 & 2 & 0.4 \\
\hline H-Jn28-1 & 52 & 4 & 2 & 2.4 \\
\hline Total & & 137 & 57 & \\
\hline
\end{tabular}

Colony designations were based on the species (D - desertorum, $\mathrm{H}$ - hyatti), the date when the colony was found (Jn - June, Jl - July, A - August) and the order in which it was found on that date. For example, H-Jn18-2 is the second P. hyatti colony found on June 18.

Activity for both species began at approximately $2000 \mathrm{hr}$ (MST) and ceased $0500 \mathrm{hr}$. To determine emigration frequency all colonies were inspected at least once daily between 2000 and $2400 \mathrm{hr}$. In order to avoid disturbing the colony any prolonged observations were made using red light. About two-thirds of the emigrations for each species were documented indirectly when a colony occupying a nest one night was found at another nest the following night. A colony was assumed to be occupying a nest if 10 foragers were 
Table 2. Emigration characteristics of $P$. desertorum.

\begin{tabular}{|c|c|c|c|c|}
\hline Colony & $\begin{array}{c}\text { Days } \\
\text { Observed }\end{array}$ & $\begin{array}{l}\text { Number of } \\
\text { Emigrations }\end{array}$ & $\begin{array}{l}\text { Returns to a } \\
\text { Former Nest }\end{array}$ & $\begin{array}{c}\text { Distance Between First } \\
\text { and Last Observed } \\
\text { Nests (m) }\end{array}$ \\
\hline D-Jn10-1 a* & 70 & 4 & 2 & 0.5 \\
\hline D-Jn11-1a & 63 & 7 & 3 & 4.8 \\
\hline D-Jn11-2a & 68 & 0 & 0 & - \\
\hline D-Jn12-1a & 60 & 4 & 1 & 15.6 \\
\hline D-Jn12-2a & 68 & 1 & 0 & 2.5 \\
\hline D-Jn12-3a & 68 & 2 & 1 & 0.0 \\
\hline D-Jn12-4a & 64 & 6 & 3 & 3.0 \\
\hline D-Jn12-5a & 21 & 1 & 0 & 4.2 \\
\hline D-Jn13-1a & 57 & 2 & 1 & 0.0 \\
\hline D-Jn14-1a & 61 & 3 & 2 & 0.0 \\
\hline D-Jn15-1a & 65 & 6 & 3 & 6.6 \\
\hline D-Jn15-2a & 62 & 3 & 1 & 0.0 \\
\hline D-Jn16-1b & 64 & 4 & 3 & 0.0 \\
\hline D-Jn17-1b & 57 & 4 & 2 & 0.0 \\
\hline D-Jn17-2b & 63 & 5 & 3 & 2.4 \\
\hline D-Jn18-1a & 49 & 3 & 1 & 3.1 \\
\hline D-Jn20-1b & 57 & 8 & 6 & 0.0 \\
\hline D-Jn25-1a & 55 & 7 & 4 & 1.5 \\
\hline D-Jn28-1a & 50 & 5 & 3 & 3.7 \\
\hline D-Jl $\quad 1-1 \mathrm{a}$ & 42 & 7 & 3 & 2.4 \\
\hline D-J1 13-1b & 37 & 2 & 1 & 0.0 \\
\hline D-J1 13-2b & 37 & 3 & 1 & 1.2 \\
\hline D-Jl 15-1b & 33 & 4 & 1 & 0.0 \\
\hline D-J1 30-1b & 20 & 6 & 3 & 0.0 \\
\hline D-Jl 30-2a & 19 & 2 & 1 & 0.0 \\
\hline D-A $1-1 a$ & 18 & 2 & 0 & 4.0 \\
\hline Total & & 101 & 49 & \\
\hline
\end{tabular}

*a: desert-grassland; b: oak-juniper woodland.

observed leaving the nest during a 1 min period. If this criterion was not met, or if there was some other reason to doubt the location of the colony, a small peanut butter bait was used to locate the colony. To avoid confusion when using this indirect method, an attempt was made to locate and mark any neighboring conspecific colonies. The remainder of the emigrations were observed directly when an emigration was discovered in progress. The nests were marked and the distance between the old and the new nests measured.

With the statistical tests employed in this paper probabilities of .05 or less were accepted as significant. 


\section{RESULTS}

Colonies of both $P$. desertorum and $P$. hyatti showed considerable variation in their frequencies of emigration (see Tables 1 and 2). One colony of each species (D-Jn11-2 and H-Jn17-1) did not emigrate at all, while one $P$. desertorum colony (D-Jn20-1) emigrated 8 times, and one $P$. hyatti colony $(\mathrm{H}-\mathrm{Jn} 14-2)$ emigrated 16 times. Despite this variability, both species showed a clear tendency to emigrate frequently: over one-half of the $P$. desertorum colonies emigrated at least 4 times, and over one half of the $P$. hyatti colonies emigrated at least 6 times. To statistically compare the emigration frequency of the two species, the percentage days for which an emigration was documented was calculated for each colony, and the percentages for each species were compared using the Wilcoxon two-sample test (Sokal and Rohlf 1969). No significant difference was found in the emigration frequency between the two species $(.1>\mathrm{P}>.05)$.

This similarity between species in emigration frequency can also be seen if the frequency of time interval between emigrations is compared. Figures 1 and 2 show the frequency of emigration interval for $P$. hyatti and $P$. desertorum, respectively. Both distributions are strongly skewed to the right with a surprisingly high number of emigrations occurring 1 to 2 days after the previous emigration. No significant difference was found in the frequency distribution between the two species (Wilcoxon two-sample test: $.4>\mathrm{P}>.2)$

The daily occurrence of emigrations among all colonies is shown in the form of frequency histograms in Figs. 3, 4 and 5. The upper line in the graphs outlines the number of colonies which were included in the sample size each night. Excluded from the sample were colonies which were raided by army ants, or were still suffering from the effects of an army ant raid (see Discussion). Superimposed over the graphs is a bar diagram showing the daily rainfall.

A positive correlation was found to exist between emigration frequency and daily rainfall in all three cases (Spearman rank correlation coefficient: $P$. hyatti $: \mathrm{r}_{\mathrm{s}}=.28, \mathrm{~N}=66 ; P$. desertorum in oak-juniper woodland $: \mathrm{r}_{\mathrm{s}}=.25, \mathrm{~N}=64 ; P$. desertorum in desertgrassland : $\mathrm{r}_{\mathrm{s}}=.32, \mathrm{~N}=70$ ). The effect of rainfall on emigration frequency is most clearly seen in $P$. desertorum in the desertgrassland habitat (Fig. 5). During the 29 days before the first heavy 
rainfall on July 9 only three emigrations occurred, but within 9 days after this rainfall 29 emigrations occurred. During this 9 day period 13 of the 15 colonies being observed on this site emigrated at least once.

The emigration distance for both species was variable. Mean emigration distance for $P$. hyatti was $1.8 \pm 1.0 \mathrm{~m}(\mathrm{~N}=137$; range 0.3 -4.9) and mean emigration distance for $P$. desertorum was $2.5 \pm$ $1.4 \mathrm{~m}(\mathrm{~N}=102$; range $0.4-6.9)$. The larger emigration distance of $P$. desertorum over that of $P$. hyatti correlates with the larger size of this species (mean length of $P$. hyatti minor $=2.64 \pm 0.04 \mathrm{~mm}$, $\mathrm{N}=50$; mean length of $P$. desertorum minor $=3.14 \pm 0.03 \mathrm{~mm}$, $\mathrm{N}=57$ ).

Despite the high emigration frequency of both species, colonies of neither species tended to move far from the nests at which they were first discovered. Tables 1 and 2 show the number of times each colony returned to a former nest, and the distance between the first and last nests. As can be seen, $49 \%$ of $P$. desertorum's emigrations, and $42 \%$ of $P$. hyatti's emigrations were to former nest sites, and 11 $P$. desertorum colonies and $5 P$. hyatti colonies at the end of the study were at the nest at which they were first discovered. This crisscrossing pattern of emigrations is illustrated for three colonies of each species in Figs. 6 and 7. The relative location of the nests reveal a clumped rather than a linear arrangement which would be expected if the colony were emigrating out of an area. The dates of nest movements for each colony show that the variability of emigration interval within each colony was considerable. This can be readily seen by examining the ranges of emigration intervals for the colonies shown in Figs. 6 and 7: for the P. hyatti colonies the ranges are, $\mathrm{H}-\mathrm{Jn} 14-2$ : 1-17 days; $\mathrm{H}-\mathrm{Jn} 14-3$ : 3-18 days; $\mathrm{H}-\mathrm{Jn} 18-1$ : 1-8 days; for the $P$. desertorum colonies the ranges are D-Jn25-1: 1-19 days; D-Jn12-4: 1-21 days; D-J130-1: 1-4 days.

Because $P$. desertorum and $P$. hyatti emigrated so frequently about $33 \%$ of the emigrations of both species were discovered in progress. These emigrations were readily noticed as hundreds to thousands of workers, most carrying brood, formed a column connecting the old nest to the new nest. The width of this column for $P$. hyatti was about $3 \mathrm{~cm}$, while for $P$. desertorum the column tended to be wider (on one occasion reaching a width of $15 \mathrm{~cm}$ ). Laboratory experiments have revealed that $P$. hyatti's emigrations 


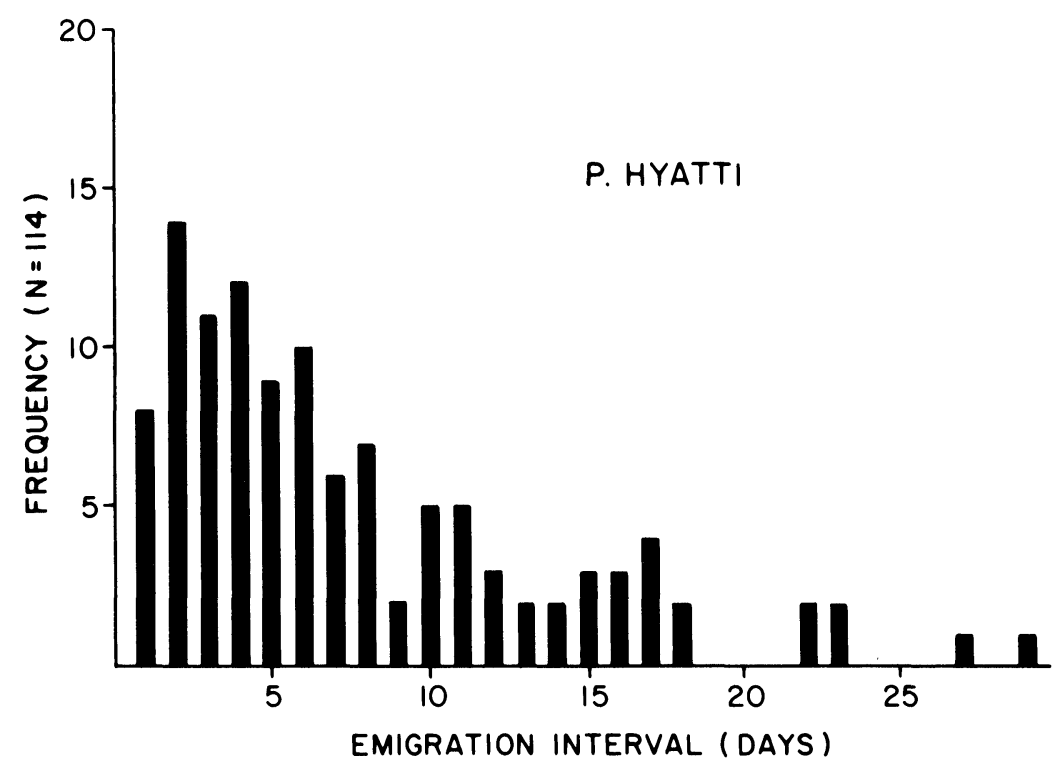

Figure 1. Frequency of the time interval between emigrations for Pheidole hyatti.

are totally organized by a substance secreted by the poison gland (Droual et al., in prep.). The queen of both species moved independently in the emigrations although she was usually surrounded by a retinue consisting mostly of minor workers (workers of the genus Pheidole are dimorphic) who tugged her by the mandibles or antennae if she hesitated en route to the new nest. During June and the early part of July alates were frequently seen in the column also moving independently. However, on one occasion, during a $P$. desertorum emigration, workers were observed carrying some of the males.

A number of phenomena related to these species' high emigration frequencies were observed. One colony of each species (D-Jn20-1 and $\mathrm{H}-\mathrm{J}$ 19-2) performed what we call an aborted emigration. In these cases the colony was observed emigrating to a new nest but on the following night was found to be back at its old nest. One $P$. desertorum colony (D-Jn-25-1) appeared to perform two emigrations in one night. On August 17 the colony was observed emigrating from nest 2 to nest 1 (see Fig. 6). However on the following night the colony was found at nest 3 . On a number of occasions an 


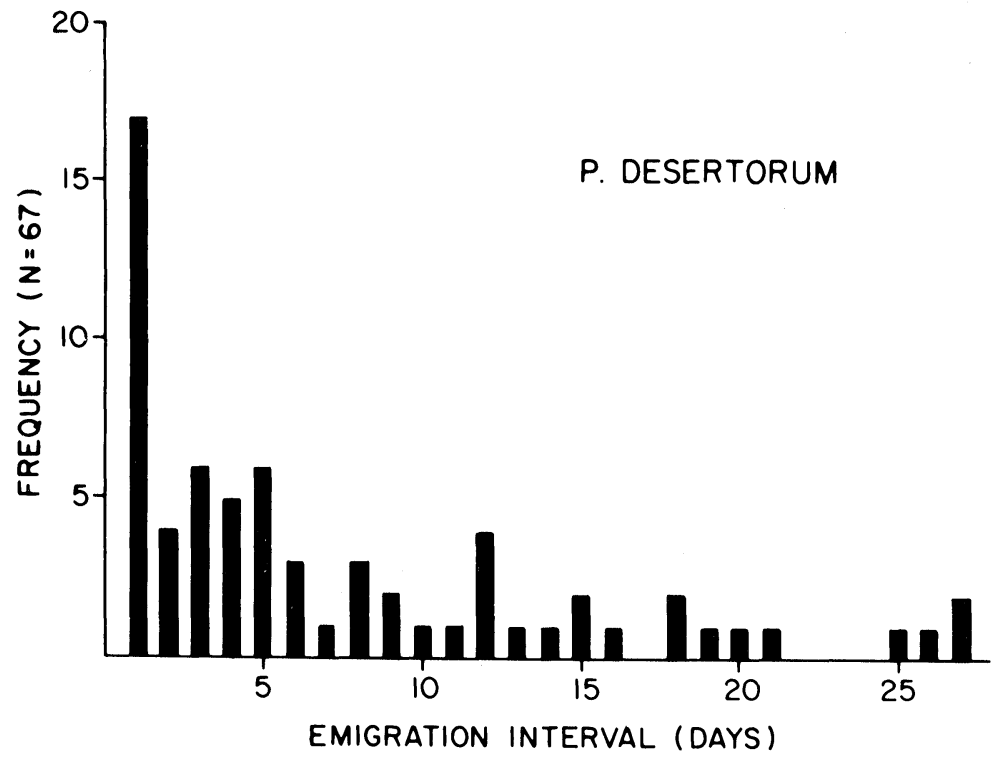

Figure 2. Frequency of the time interval between emigrations for Pheidole desertorum.

emigration could be predicted in advance by the colony's excavation activity at another site. For example, before colony D-Jn12-2 emigrated to its second nest site on $8 / 17$, workers from the colony were observed excavating at the site on $8 / 4,8 / 5,8 / 7$ and $8 / 10-8 / 17$. However two colonies of both $P$. desertorum and $P$. hyatti were observed excavating at sites to which they did not emigrate even though they emigrated later to other nests.

\section{Discussion}

In this paper we have shown that $P$. desertorum and $P$. hyatti emigrate frequently and that the emigration frequencies of the two species are similar. This similarity in emigration frequency becomes even more marked when it is taken into account that most of $P$. desertorum's emigrations in the desert-grassland occurred after the first rainfall. The sharp increase in emigration activity after the rain can possibly be explained by the affect of the rainfall upon the soil. Before the rains began the soil was very hard and compact, but after 


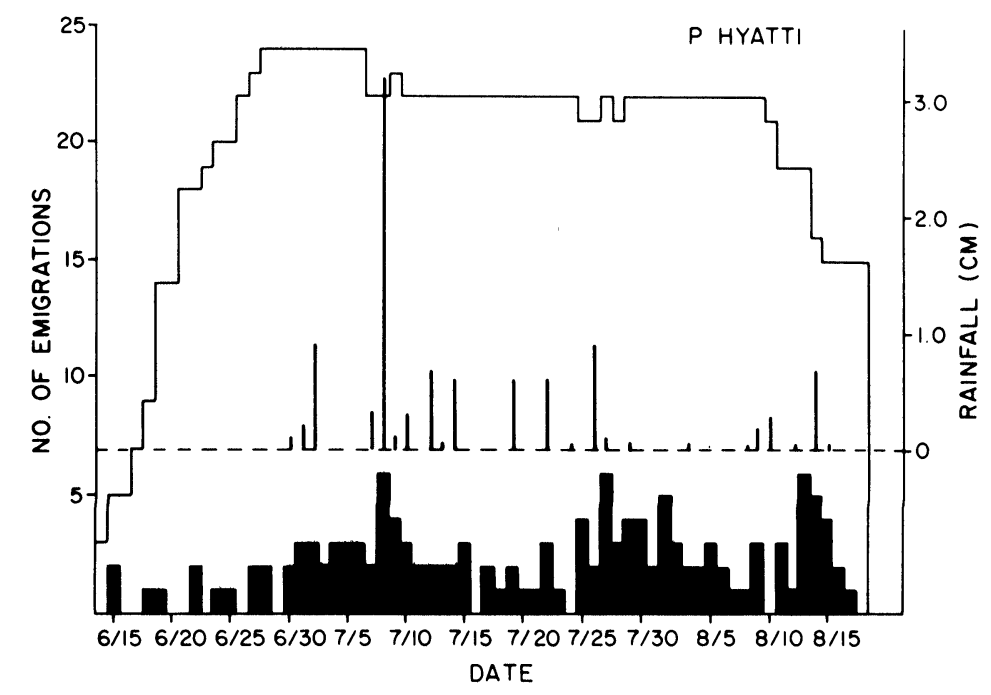

Figure 3. Daily occurrence of emigrations for Pheidole hyatti. Black bars indicate the number of colonies which emigrated each night. Upper line outlines the number colonies included in the sample each night. Right ordinate indicates rainfall for the superimposed bar diagram showing daily rainfall.

the first heavy rainfall the soil loosened considerably. This undoubtedly made the excavation of new nests by the desert-grassland $\mathrm{d}$ welling colonies much easier. The same reasoning can be applied to explain the positive correlation between emigration frequency and daily rainfall in both habitats. However, in the oak-juniper woodland, the greater amount of vegetation, the rockier soil and the generally moister conditions probably account for the relatively higher emigration activity before the beginning of the rainy season in this habitat.

The need to perform a colony emigration is a contingency almost all species of ants can be expected to face (Wilson 1971). However some species emigrate more than others. Among the legionary ants, particularly the Ecitoninae and Dorylinae, colony emigrations are an integral part of the foraging ecology (Wilson 1971). Opportunistic nesters such as Tapinoma melanocephalum, T. sessile, Paratrechina bourbonica and $P$. longicornis occupy ready-made nests such as the tufts of dead grass and hollow plant stems which 


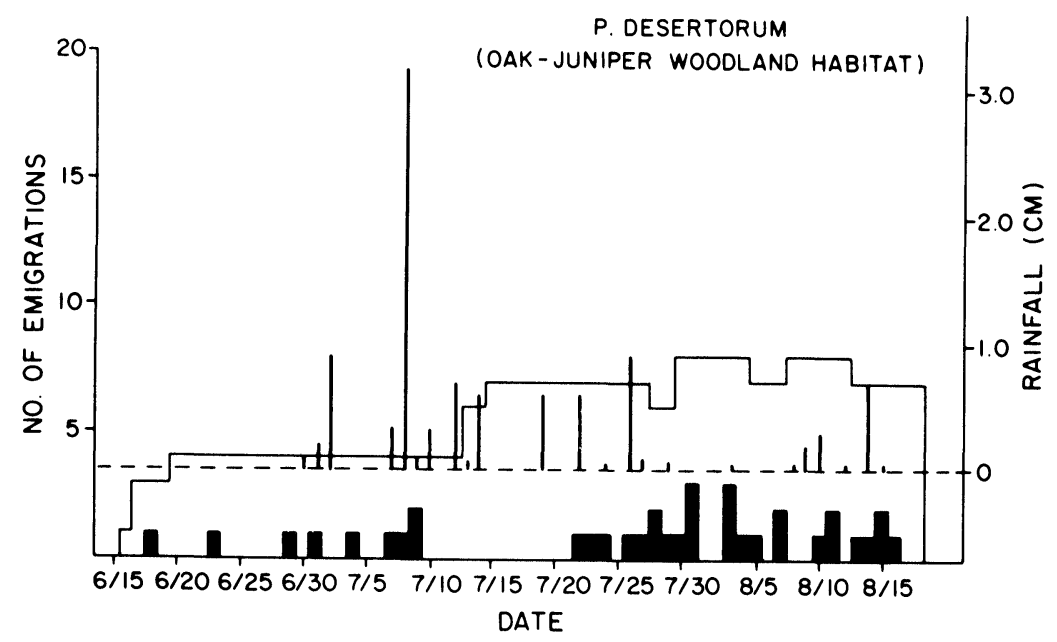

Figure 4. Daily occurrence of emigrations for Pheidole desertorum in oakjuniper woodland (See Fig. 3).

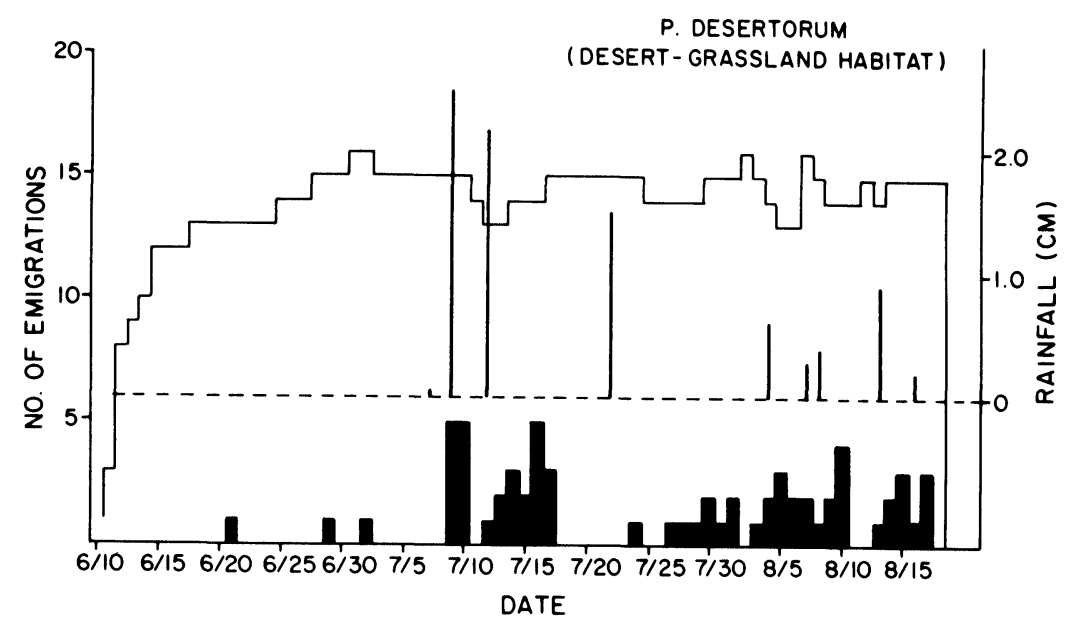

Figure 5. Daily occurrence of emigrations for Pheidole desertorum in desertgrassland (see Fig. 3). 


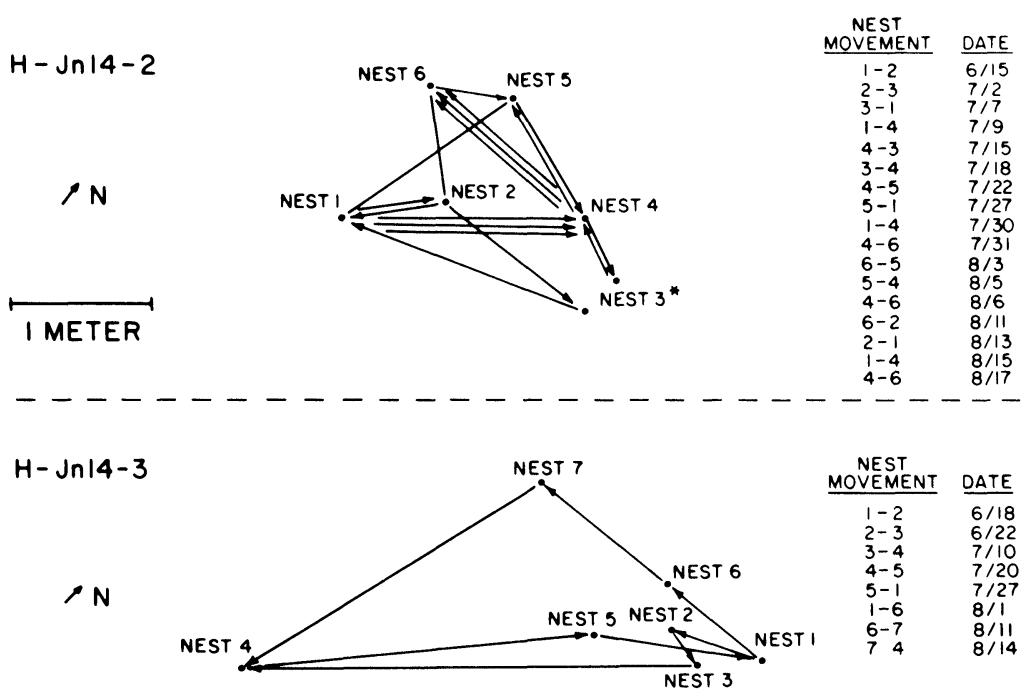

I METER

$H-J n 18-1$

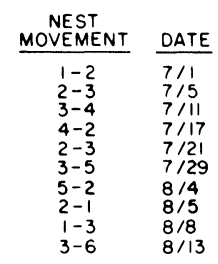

IMETER

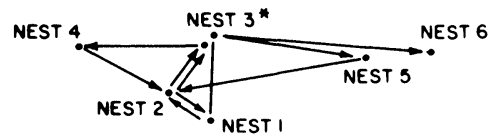

Figure 6. Pạtterns of emigrations for three colonies of Pheidole hyatti. Dates of nest movements are shown on the right. *This nest had two entrances.

are short-lived. When these nests are disturbed, the colonies quickly organize emigrations to other such nests (Hölldobler and Wilson 1977). Leptothorax acervorum in oak-juniper woodland, construct delicate nests under stones which can be easily dislodged by large vertebrates, and are prone to emigrate when their nest is disturbed (Möglich 1979).

Most species build or choose nest sites which are longer-lived and less easily disturbed and are thought to emigrate infrequently. Among these species emigrations can be due to a local factor such as 
$D-\ln 25-1$

$N$

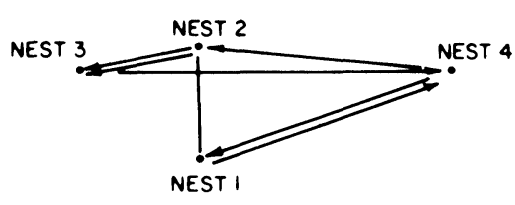

NEST
MOVEMENT DATE

$\begin{array}{lll}1-2 & 7 / 12 \\ 2-3 & 7 / 15\end{array}$

$\begin{array}{ll}2-3 & 7 / 15 \\ 3-4 & 7 / 16\end{array}$

$4-1 \quad 8 / 5$

$1-4 \quad 8 / 6$

$\begin{array}{ll}4-4 & 8 / 15 \\ 4-2 & 8 / 15 \\ 2-3 & 8 / 17\end{array}$

I METER

- - - - - - - - - - - - - - - - - - - - - - -

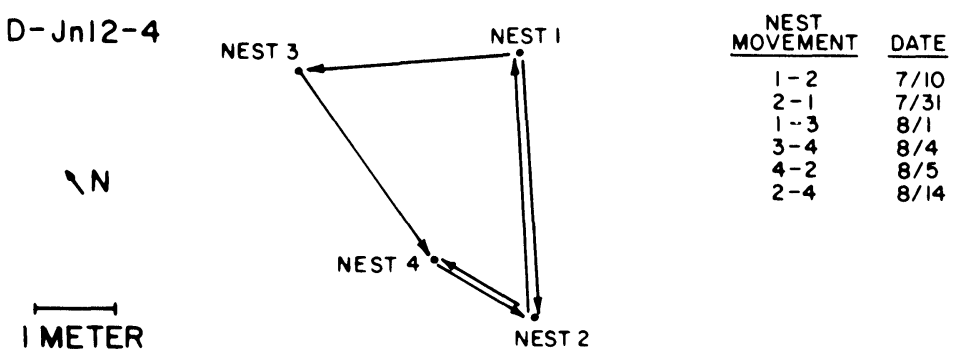

$D-J 130-1$

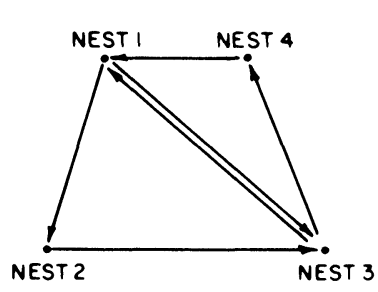

\begin{tabular}{ccc} 
NEST & \\
MOVEMENT & & DATE \\
\cline { 1 - 1 } $1-2$ & & $7 / 31$ \\
$2-3$ & & $8 / 3$ \\
$3-1$ & & $8 / 7$ \\
$1-3$ & & $8 / 11$ \\
$3-4$ & & $8 / 15$ \\
$4-1$ & & $8 / 16$
\end{tabular}

\section{METER}

Figure 7. Patterns of emigrations for three colonies of Pheidole desertorum. Dates of nest movements are shown on the right.

shading (Brian 1956, Carlson and Gentry 1973), or climatic adversity such as drought or frost (Brian 1952). A colony may also be forced to emigrate because of some biotic factor such as inter- and intra-specific competition (Hölldobler 1976, Waloff and Blackith 1962, Brian 1952, Brian et. al. 1965) and predation (Gentry 1974).

The view that emigrations occur infrequently among most ants 
was recently challenged by Smallwood and Culver (1979). These investigators conducted a study in which they found that Tapinoma sessile and Aphaenogaster rudis emigrated frequently. Their study differs from ours in that colonies were marked and rechecked only after intervals of 11-21 days and no attempt was made to follow the behavior of individual colonies. Because $T$. sessile and $A$. rudis choose different nesting sites and have different life styles these investigators deduced that emigrations occur more frequently among ants than had been previously thought. However, the fact that $T$. sessile, as mentioned above, is an opportunistic nester which is expected to emigrate frequently weakens their argument.

It is difficult to apply any of the known or previously hypothesized causes of colony emigrations to explain the frequent emigrations of $P$. desertorum and $P$. hyatti. The nests of both species are excavated in the soil to a depth of 30 to $40 \mathrm{~cm}$ (based on excavations in oak-juniper woodland), and hence are not easily disturbed. Shading is obviously not a factor in the desert-grassland, and is negligible in the oak-juniper woodland where the canopy is not extensive. Permanent deterioration of the nest as a cause is eliminated by the fact that colonies return to former nests. Indeed almost half of all emigrations for both species resulted in a return to a former nest. This fact, and the patterns of emigrations which tended to keep a colony in the same area, argue against any hypothesis which involves a deterioration of some local condition such as might be due to interference competition or to a decrease in the local food supply.

However, in one instance the possibility that an emigration may have been the result of intraspecific competition should be mentioned. This involved colony $\mathrm{H}-\mathrm{Jn} 14-1$ which was observed emigrating a distance of $4.9 \mathrm{~m}$ the day after it was found. This distance is considerably larger than the mean emigration distance of $1.8 \mathrm{~m}$ found for $P$. hyatti. Four days later, colony $\mathrm{H}-\mathrm{Jn} 19-1$ was discovered emigrating $2.3 \mathrm{~m}$ into the nest vacated by colony $\mathrm{H}-\mathrm{Jn} 14-1$. Although large-scale conflicts between these species were never observed, workers will attack any alien workers of either species discovered near their nest. Frequent encounters of this sort may have caused colony H-Jn14-1 to make its unusually long emigration.

In discussing the causation of any behavior a distinction should be made between those hypotheses that invoke a proximate cause 
and those that invoke an ultimate cause (Wilson 1971). For example, it has been hypothesized that the ultimate cause of army ant emigrations is to prevent a local depletion of food resources (Wilson 1971). The proximate cause of these emigrations, at least among the Ecitoninae, was discovered to be recruitment to a new nest under periods of high colony arousal due to brood stimulation (Schneirla 1938). However, it has been recently shown that food supply may also be a proximate factor (Topoff and Mirenda 1980, Mirenda and Topoff 1980). The hypothesis we are advancing to explain the frequent emigrations of $P$. hyatti and $P$. desertorum concerns the ultimate cause of these emigrations although both the ultimate and proximate causes are the subject of further investigation by us.

Both $P$. desertorum and $P$. hyatti, which are small and lack potent stings, are easy prey for army ants of the genus Neivamyrmex. Mirenda et. al. (1980) found, in the same desert-grassland site employed in this study, that $P$. desertorum was the species most frequently raided by $N$. nigrescens. Our own observations also show that both $P$. desertorum and $P$. hyatti are heavily preyed upon by members of the genus Neivamyrmex (Tables $3 \& 4$ ). Some $P$. desertorum colonies were raided repeatedly by the same army ant colony which entered the statary phase in a nearby bivouac. On two occasions an army ant colony actually bivouacked in the evacuated nest of a $P$. desertorum colony. One $P$. hyatti colony was raided by two species of Neivamyrmex. Of these colonies only five appeared to be completely eliminated by the army ants. Part of the reason for

Table 3. Observed army ant raids on colonies of P. hyatti.

\begin{tabular}{lcl}
\hline Colony & Dates of Raids & \multicolumn{1}{c}{ Species Raiding } \\
\hline H-Jn15-1 & $7 / 7,7 / 8^{*}$ & Neivamyrmex nigrescens \\
H-Jn15-2 & $7 / 8$ & $N$. nigrescens \\
H-Jn19-4 & $7 / 28$ & $N$. texanus \\
H-Jn21-3 & $8 / 15$ & $N$. opacithorax \\
H-Jn21-4 & $8 / 17$ & $N$. nigrescens \\
H-Jn21-5 & $8 / 15$ & $N$. opacithorax \\
& $8 / 18$ & $N$. nigrescens \\
H-Jn23-1 & $8 / 15^{*}$ & $N$. opacithorax \\
H-Jn26-1 & $8 / 12$ & $N$. nigrescens \\
H-Jn27-1 & $8 / 12^{*}$ & $N$ nigrescens \\
\hline
\end{tabular}

*Colony was not seen afterwards. 
this is the panic-alarm defense employed by these species against the army ants.

That defense behavior in ants can be both enemy specific and complex was established with the discovery of the alarm-recruitment defense of Pheidole dentata against the fire ant Solenopsis geminata (Wilson 1975 and 1976). Although more evidence is necessary, the defense behavior of $P$. hyatti and $P$. desertorum appears to be both enemy specific and complex. The defense, which begins when a Pheidole forager contacts an army ant and runs back into the nest raising an alarm, occurs in two phases. In the first, or "milling", phase, workers carrying brood well out of the nest but remain in close contact near the nest's entrance. In the second, or absconding, phase, the workers flee from the nest. P. desertorum's flight is protean in nature (Humphries and Driver 1970) with workers scattering in all directions. In $P$. hyatti the exodus is more organized with the workers fleeing in columns which appear to follow recently-laid chemical trails.

After evacuating from their nest the fleeing workers tend to concentrate at temporary shelters such as that provided by leaf litter, fallen branches, rotting logs and tufts of grass. Some workers eventually find some or all of the former nests and begin to recruit other workers to them. After the raid is over workers will also start to return to the evacuated nest. In this manner the colony becomes fragmented with various proportions of the colony in some or all of the available nests. The colony then begins the process of reorganizing with segments in one nest emigrating to join segments in another nest until the colony becomes reunited in one nest. Hence it appears that the surplus nests resulting from the frequent emigrations of these species serve a dual purpose after an evacuation: they provide shelter and centers for reorganization.

After a nest evacuation, finding a place of suitable moisture before the lethal surface temperatures and low surface humidity of the approaching day is undoubtedly of vital importance for these nocturnal species. This problem becomes particularly severe in the desert-grassland where the lack of ground cover makes nests excavated in the ground the only suitable shelters. Having alternate nests becomes a necessity when an army ant colony bivouacs in the evacuated nest. The hypothesis we are proposing then is that the surplus nests which result from the emigrations of these species increases the effectiveness of the panic-alarm defense by reducing 
Table 4. Observed army ant raids on colonies of $P$. desertorum.

\begin{tabular}{lcl}
\hline Colony & Dates of Raids & \multicolumn{1}{c}{ Species Raiding } \\
\hline H-Jn11-1 & $8 / 1-8 / 5$ & Neivamyrmex nigrescens \\
H-Jn1 1-2 & $7 / 9$ & $N$. nigrescens \\
H-Jn12-1 & $8 / 4,8 / 6,8 / 8$ & $N$. nigrescens \\
H-Jn12-4 & $7 / 4$ & $N$. nigrescens \\
H-Jn12-5 & $7 / 2^{*}$ & $N$. nigrescens \\
H-Jn13-1 & $7 / 12,8 / 10^{*}$ & $N$. nigrescens \\
H-Jn14-1 & $8 / 5,8 / 6,8 / 12-8 / 15$ & $N$. nigrescens \\
H-Jn18-1 & $7 / 11,7 / 12,7 / 16$, & $N$. nigrescens \\
& $7 / 25,7 / 26,7 / 28,8 / 1$ & \\
H-Jn17-1 & $8 / 18$ & $N$. nigrescens \\
H-Jn25-1 & $8 / 28$ & $N$. nigrescens \\
H-J1 4-1 & $8 / 3,8 / 5-8 / 7,8 / 9$ & $N$. nigrescens \\
H-J1 30-2 & $8 / 13$ & $N$. nigrescens \\
H-J1 15-1 & $7 / 28$ & $N$. texanus \\
\hline
\end{tabular}

${ }^{*}$ Colony not seen afterwards.

the secondary losses which result from the disorganization which follows the defense. If this hypothesis proves to be correct, the possibility that the frequent emigrations of these species have evolved to serve as part of a defense system against the army ants has to be entertained.

\section{ACKNOWLEGEMENTS}

This research was supported by a N.I.M.H. training grant (MH 15341), a Theodore Roosevelt Memorial Fund Grant, PSY-CUNY Grant 13492 and a NSF Grant BNS- 8004565. We thank Dr. G. Turkewitz for his statistical advice and Roy R. Snelling for identifying the Pheidole specimens.

\section{Literature Cited}

BrIAN, M. V.

1952. The structure of a dense natural ant population. J. Anim. Ecol. 21: 12-24.

1956. Segregation of species of the ant genus Myrmica. J. Anim. Ecol. 25: 319-337.

Brian, M. V., J. Hibble and D. J. Stradling.

1965. Ant pattern and density in a Southern English heath. J. Anim. Ecol. 34: 545-555.

Carlson, D. M. and J. B. Gentry.

1973. Effects of shading on the migratory behavior of the Florida harvester ant, Pogonomyrmex badius. Ecology 54: 452-453. 
Gentry, J. B.

1974. Response to predation by colonies of the Florida harvester ant, Pogonomyrmex badius. Ecology 55: 1328-1338.

HöLLDOBLER, B.

1976. Recruitment behavior, home range orientation and territoriality in harvester ants, Pogonomyrmex. Behav. Ecol. Sociobiol. 1(1): 3-44.

HöLlDOBLER, B. AND E. O. Wilson.

1977. The number of queens: an important trait in ant evolution. Naturwissenshaften 64: 8-15.

Mirenda, J. T., D. G. Eakins, K. Gravelle and H. Topoff.

1980. Predatory behavior and prey selection by army ants in a desert-grassland habitat. Behav. Ecol. Sociobiol. 7: 119-127.

Mirenda, J. T. and H. Topoff.

1980. Nomadic behavior of army ants in a desert-grassland habitat. Behav. Ecol. Sociobiol. 7: 129-135.

MöGLICH, M.

1978. Social organization of nest emigration in Leptothorax. (Hym. Form.). Ins. Soc. 25(3): 205-225.

SChNeirla, T. C.

1938. A theory of army-ant behavior based upon the analysis of activities in a representative species. J. Comp. Psychol. 25: 51-90.

Smallwood, J. and D. C. Culver.

1979. Colony movements of some North American ants. J. Anim. Ecol. 48: 373-382.

SOKAL, R. R. AND F. J. ROHLF.

1969. Biometry. W. H. Freeman and company, San Francisco, xxi +776 p.

TopofF, H. AND J. MiRenda.

1980. Army ants of the move: relation between food availability and emigration frequency in Neivamyrmex nigrescens. Science 207: 1099-1100.

WaLOFF, N. AND R. E. BLACKith.

1962. The growth and distribution of the mounds of Lasius flavus (Fabricius) (Hym:Formicidae) in Silwood Park, Berkshire. J. Anim. Ecol. 31: 421-437.

WILSON, E. O.

1971. The Insect Societies. Belknap, Harvard Univ. Press, Cambridge, $x+548$ p.

1975. Enemy specification in the alarm-recruitment system of an ant. Science 190: $798-800$.

1976. The organization of colony defense in the ant Pheidole dentata Mayr (Hymenoptera: Formicidae). Behav. Ecol. Sociobiol. 1: 63-81. 

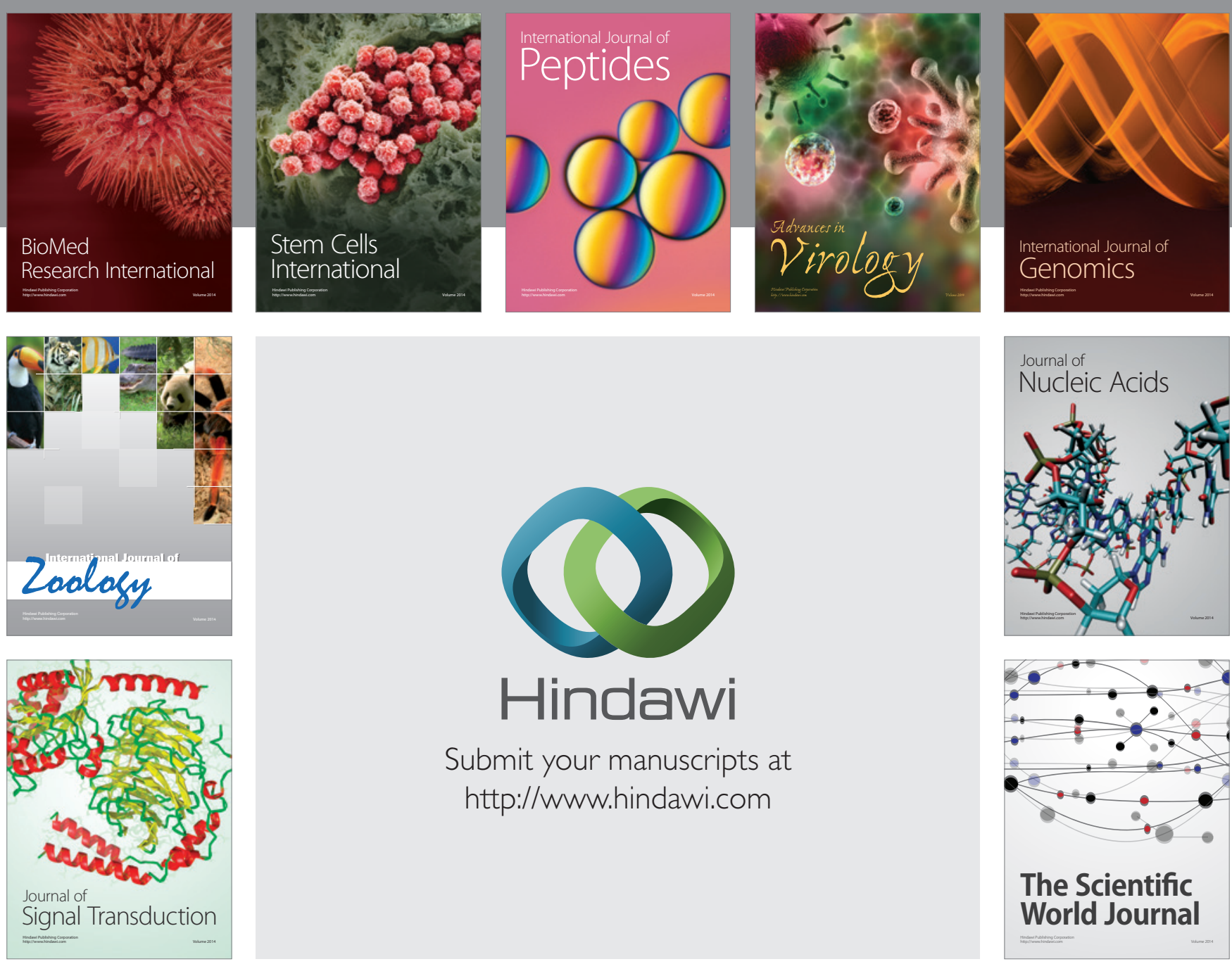

Submit your manuscripts at

http://www.hindawi.com
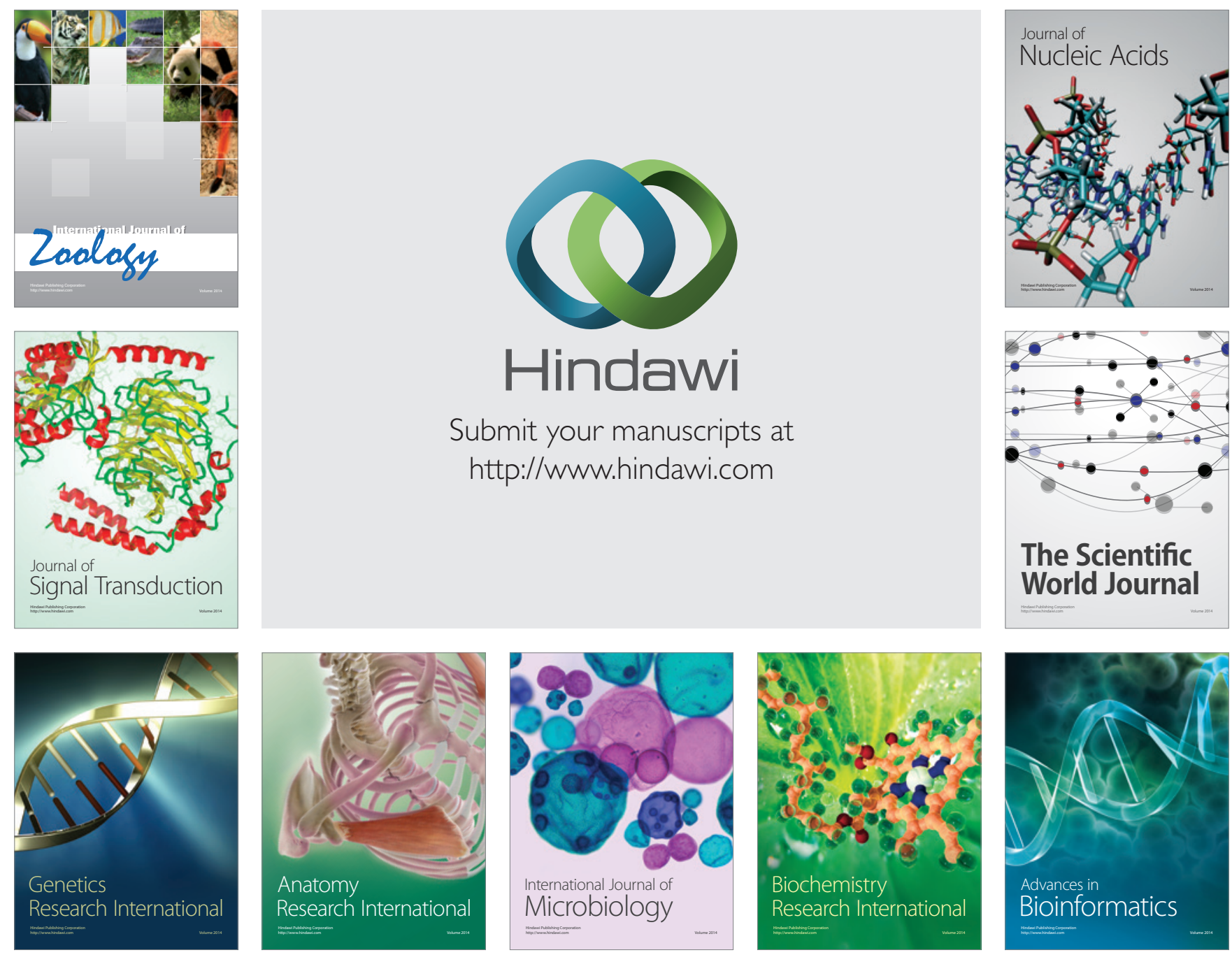

The Scientific World Journal
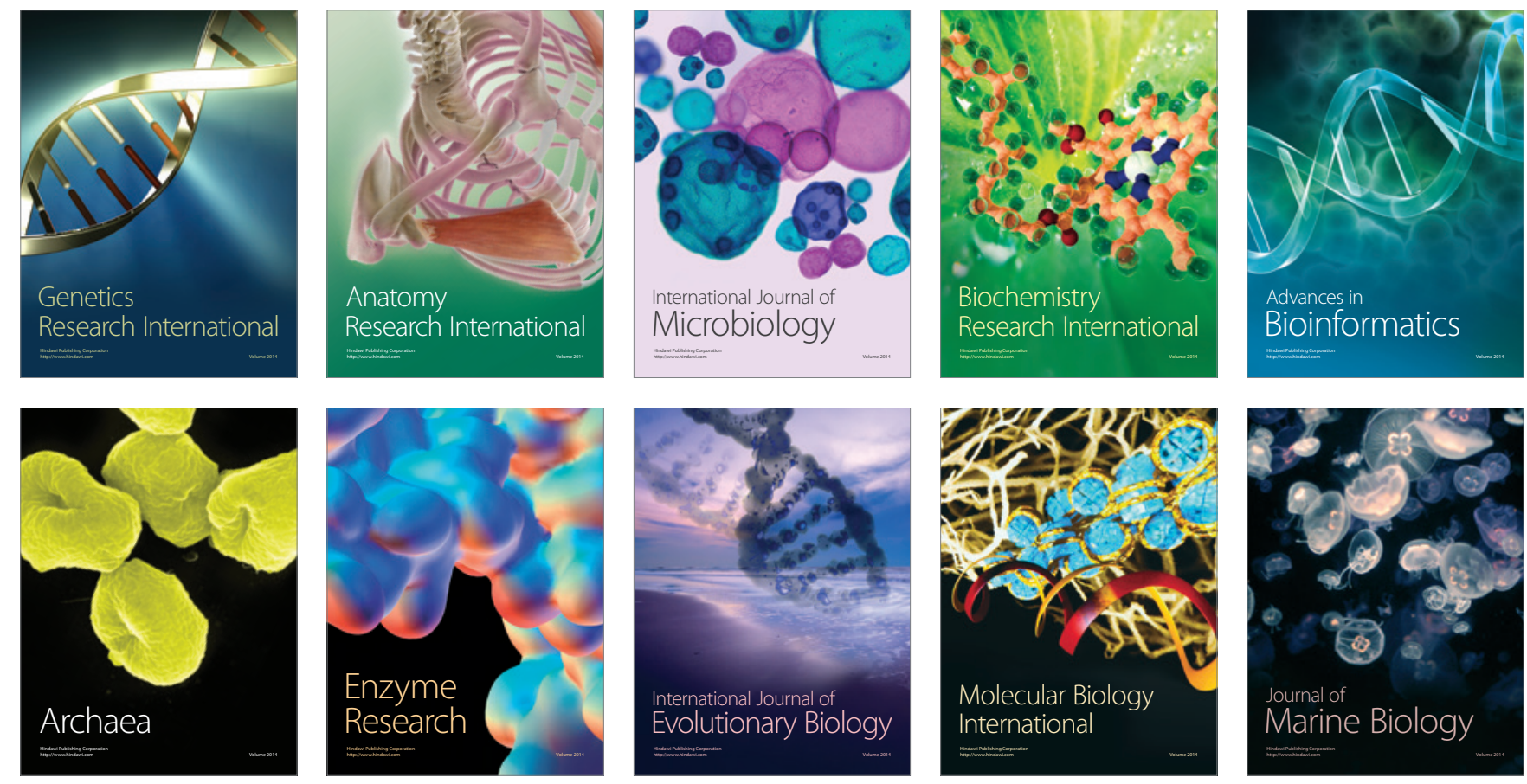